\title{
EFFECTS OF SON PREFERENCE ON FERTILITY: A PARITY PROGRESSION ANALYSIS
}

\author{
MOHAMMAD NAZMUL HOQ ${ }^{l}$
}

\begin{abstract}
This article assesses the strength of son preference in Bangladesh, as reflected in fertility behavior. Although the fertility rate for Bangladesh declined from 6.3 children per woman of reproductive age in the year 1975 to 2.3 children in 2014, empirical results show that son preference has still a strong influence on fertility behavior. Keeping cognizant of this fact, this study examines levels and differentials in fertility and also investigates the effects of son preference on fertility in Bangladesh. In addition, the study inspects the underlying factors responsible for son preference. Levels of fertility indicate that the proportion of higher education of a couple is inversely related to fertility, whereas rural and Muslim couples in Bangladesh have more children. The bivariate analysis shows that almost all the independent variables selected for this study have a significant association with parity progression. Findings from multivariate analyses suggest that women with at least one son are less likely to continue childbearing than women without sons at parities 2-3. At most or all parities, continued childbearing is negatively associated with education, access to mass media, and family wealth. A significant source of motivation for parity progression in couples is the desire to have a son.
\end{abstract}

KEYWORDS: fertility, son preference, socioeconomic and demographic variables, parity progression, Bangladesh

\section{INTRODUCTION}

The population of Bangladesh is increasing at an annual growth rate of 1.37 percent (Census 2011), or 1.05 percent according to the World Bank (2017). The present rate of population growth is one of the burdens on the development of Bangladesh. Over the last half-century, the consensus has emerged that the

1 Mohammad Nazmul Hoq is assistant professor of statistics, Department of Business Administration, International Islamic University Chittagong, Bangladesh; e-mail: ronyfirst@yahoo.com 
growth rate of the population is having substantial effects on the development of the country. For a long time the issue of fertility decline leading to a population decline and its potential link to economic growth has been contemplated. Evidence for the economic effects of fertility is strong. Various factors such as education, industrialization, and the increase of different human indices point out that structural development in a country serve to reduce fertility. This paper aims to bridge the gap between understanding the relationship of fertility and socioeconomic development by studying son preference in Bangladesh.

In demography, the word fertility is used to measure the actual production of children or the occurrence of births, especially live births. One simple measure of fertility is the average number of children born per woman. The estimated quantity of children that will be born to a specific woman at any point is thus a total measure of her lifetime fertility that is valid at the time which the related information is gathered. Without a conscious consolidated push to control the extent of families, the large portion of the population who are within the fertile age group will add to population growth, and this will impact the population structure in terms of reducing the average age.

In a developing country, financial factors significantly affect preferences for children, especially sons. In many Asian countries, married children are required to live with aged parents and provide financial support to them. When a girl marries, she joins her other half's family unit and does not regularly contribute to her own parents' upkeep. Her marriage itself may represent a significant monetary burden due to the desire for a great festival, as is typical in most South Asian countries, as is the payment of a dowry, especially in India and Bangladesh. This dowry tradition is found in low-level income status families in these two regions. Prominently, South Asian countries have seen fertility trends progress in nearly similar ways since the late 1970s or mid-1980s despite the fact that these countries have adequately developed the standard preconditions for a decrease in fertility - for example, massive progress in financial status, positive changes in maternal well-being, a significant reduction in child mortality, an increase in the time between marriage and childbearing, and extensive advances in the status of women (Basu - Amin 2000; Chattopadhyay - Goswami 2007). Huiying (2016) demonstrated that the main reason for son preference in rural China is the patriarchal family system, and also the imbalance in the sex ratio at birth. In Bangladesh, biased gender norms prevail among the Muslim and Hindu community and even at the national level (Visaria 2015). Moreover, the motivation for son preference differs from culture to culture, although the primary driver of son preference is rooted in the organization of society along patrilineal lines. The rigidity and strength of patrilineal practices in many countries affects the preference for sons over daughters (Boer - Hudson 2017). 
However, a decrease in fertility is bought about by mortality in all age groups (Kabeer et al. 2014). Therefore, in this study an attempt has been made to quantitatively assess how son preference affects fertility in a developing country like Bangladesh, where initial fertility levels are still high.

\section{LITERATURE REVIEW}

Most people in Bangladesh have a strong desire for sons, and it is not difficult to understand the reasons for this. The emphasis may be attributed to the cultural traditions in Bangladesh, which include restrictions on women moving freely outside the home for any purpose, and the culture of awarding men the responsibility of providing for the basic needs of the family. As a result, men are awarded special privileges regarding access to property and jobs.

Women are thus dependent on the male individuals in their families - first to their fathers, then after marriage to their husbands, and finally, at an older age, to their sons - given that they are sufficiently lucky to have sons. Daughters are viewed as an economic liability in many developing countries, mainly South Asian nations, and are pushed to marry as quickly as time permits with the goal of offloading the expense of sustaining them to their husband.

The practice of awarding a dowry is as yet a comparatively new phenomenon in Bangladesh, but has made the related issues worse. Sons represent protection and resources against destitution in advanced age and having a larger family guarantees that in any event some sons will be available to take care of their aged parents. One obvious approach to countering the expense of having numerous children is to let less-esteemed female children perish - most often through malign neglect (Kabeer et al. 2014). National-level gender preferences for children not only give rise to a skewed gender ratio but also change couples' fertility-related behavior. Parents who want at least one offspring of a specific sex tend to have bigger families (Seidl 1995).

For the most part, parents with a preference for children, especially sons, will keep on bearing kids until they succeed in having the number of children of the desired sex, given the family's financial situation (Basu - Jong 2010). Moreover, intervals between births are shorter in many African and South Asian countries after the birth of a daughter compared to the post-birth interval after sons are born (Rahman - Vanzo 1993; Leone et al. 2003; Mace - Sear 1997). The gender of previous children has an impact on couples' fertility expectations, so fertility may even be expected to increase, in contrast to the trend in industrialized nations for standard family sizes to decline, indicating that the factors that influence the choice to have another child are of essential importance (Sloane - Lee 1983; 
Wood - Bean 1977). It is along these lines especially fascinating to think about sex preferences and their demographic effects in a contemporary low-fertility setting, which approach has, as a rule, been ignored by demographers so far (Hank - Kohler 2000).

Son preference is by and large seen as a socially decided predisposition; in a male-centric culture, couples prefer to bring up a child who has socially acknowledged attributes, status, and financial potential. This preference typically impacts behavior and may bring about favoritism that adversely influences the welfare, well-being and survival of girls and women. In this way, preferences may prompt gender discrimination (Leone et al. 2003).

Although a preference for children is regularly thought to be a noteworthy obstruction to decreasing fertility, no predictable affiliation has been identified between control of fertility and the sex of children. To better comprehend son preference, it is imperative to understand as a primary driver the financial and social setting of a nation. As son preference is to a great extent a sociocultural phenomenon, its impact ought not to be belittled in traditional poor societies (Khan - Khanum 2000).

The pervasiveness of son preference in itself means lowering the status of women. Wherever a preference for sons is robust, it tends to be accompanied by unjust practices towards daughters, many of which have immediate or potentially long-term negative outcomes for their well-being and prosperity. Quantitative information about the pervasiveness of son preference has been acquired by demographers interested in its effect upon fertility levels.

These days, fewer women need fewer kids, disregarding whether they are boys or girls. Without a doubt, some also express a preference for daughters. Evidence indicates that women are in reality better educated than in the past, and are earning better incomes (Thompson - Sanabria 2010; Schurmann 2009; Ministry of Environment and Forests 2012). Microloans for women have expanded through enlisting women in the expanding area of NGOs, the ascent of an export-oriented garment industry, and even the Green Revolution in farming, which factors have additionally created more interest in women's work (Alamgir 2009; Zaman 2004). Women presently enter marriage on far less needy terms than previously, and are less eager to endure harsh spouses and in-laws.

There are many factors which are having a significant influence on reducing the fertility rate, although son preference is one of the elements which remains a barrier to reducing fertility. Most studies have concentrated on understanding the association between gender-based preferences for children and desired fertility outcomes (Adebowale - Palamuleni 2015; Calhoun et al. 2013; Kamal - Chaudhury 2003). There is less research about how son preference affects fertility that has investigated the probability of parity progression. This paper 
addresses the research gap by examining the effects of respondents' demographic characteristics and different socioeconomic factors on fertility using parity progression analysis. Thus the objective of this research is to study the impact of gender preferences for children, especially son preference, on fertility in Bangladesh.

\section{MATERIALS AND METHODS}

This study utilizes data extracted from the 2014 Bangladesh Demographic and Health Survey (BDHS 2014), in which fieldwork was conducted from June 28, 2014 to November 9, 2014 in four phases on behalf of the Government of Bangladesh by the National Institute for Population Research and Training (NIPORT), with funding from the United States Agency for International Development (USAID). A total of 18,245 women aged 15-49 that had married at least once were identified and 17,863 were interviewed, with a response rate of 98 percent.

The principal explanatory variable of interest is son preference in relation to the survival of children. A proxy variable of fertility is used here to estimate the level of fertility, which is defined as the number of living children. To encourage complete reporting, each woman who was interviewed was asked for information about the number of children living with her or living somewhere else, and the number who had died. The study included currently married respondents who have surviving children to measure their level of fertility. The dependent variables of the study are the four binary variables of women's parity progression - i.e. parity movement from 1 to 2 , from 2 to 3 , from 3 to 4 and from 4 to 5 . At each parity, the sample includes those respondents who continued up to parity 6 and further.

The probable consequence of son preference is gender discrimination in education, health, and other outcomes (Chaudhuri 2012). Chaudhuri focused on the implications of different explanatory variables on women's parity progression which is driven by a desire for sons. This study presents a vigorous analysis of the consequence of the desire for sons on parity progression. For this reason, this study considers several explanatory variables to measure the level of fertility which is likely to influence parity progression.

The education of the respondents and their partners (no education, primary, secondary, and higher education) may be an important determinant of fertility. The analysis included socioeconomic measures which included the working status of the respondent (working at the time of the survey or not), religion (Muslim or Non-Muslim), partner's occupation (agriculture, service, business, 
and other), and socioeconomic status (poor, middle, and rich). Other measures used in the analysis were age at first marriage (median age was used in recoding), place of residence (urban or rural), and marital duration (the difference between current age of respondent and age at first marriage). A media exposure index indicated whether the respondent used TV, radio or print media (categorized as ' 0 ' if they never used any of the media, and ' 1 ' if they indicated they used at least one of the media sources).

The relationships between fertility and selected explanatory variables were tested by applying cross-tabulation analysis which is an essential first step for studying the relationship between fertility and several of the respondents' demographic characteristics. However, the cross-tabulation analysis fails to address the predictors of levels of fertility entirely because it potentially ignores other covariates. Hence, multivariate logistic regression analysis was also used with the specific end goal of evaluating the autonomous impacts of every factor while controlling for the others.

\section{THE POPULATION OF BANGLADESH AND FERTILITY TRENDS}

Before estimating fertility differentials, it is necessary to know the overall fertility-related patterns of the population in Bangladesh after independence to the present time. The study considered different decennial censuses and organizations' reports containing inter-census data to obtain an idea about the size of the population in the period 1974 to 2017, as displayed in Table 1.

Table 1 Total population of Bangladesh according to different censuses and surveys

\begin{tabular}{|c|c|c|}
\hline Sources & Year & Population (millions) \\
\hline National Census & 1974 & 76 \\
\hline National Census & 1981 & 87 \\
\hline National Census & 1991 & 112 \\
\hline National Census & 2001 & 129 \\
\hline UN Population Fund & 2003 & 150 \\
\hline UN Dept Economic and Social Affairs & 2005 & 142 \\
\hline UN Population Fund & 2006 & 144 \\
\hline UN & 2007 & 159 \\
\hline World Bank & 2008 & 160 \\
\hline World Population Reference & 2010 & 164 \\
\hline National Census & 2011 & 149.77 \\
\hline Bangladesh Bureau of Statistics & 2017 & 158.5 \\
\hline
\end{tabular}


According to the Bangladesh Bureau of Statistics, the total population of Bangladesh is about 158.5 million, which ranks it as the eighth most populous country in the world. Three decades ago, this figure was only 87 million while it was 129 million one decade later. The increasing population growth is better understood by studying the total fertility rate.

Total fertility rate means the average number of children a woman would have if she were to advance through all her childbearing years in a single year. Moreover, this indicator refers to the number of children a woman would have if her fertility were typical of the prevailing fertility rates of women of all ages in a single given year through the entirety of her childbearing years. The total fertility rate is thus a better index of fertility than the crude birth rate since it is autonomous of the age structure of the population. However, it is a poorer gauge of actual data than the total cohort fertility rate, which is acquired by summing the age-specific fertility rates that are associated with every cohort as women age over time.

Fertility trends in Bangladesh can be examined by comparing age-specific fertility rates over time from the 1975 Bangladesh Fertility Survey (BFS) to data from the 2014 Bangladesh Demographic Health Survey (BDHS). To understand the patterns of TFR at a glance, the computed TFR is also displayed in Table 2.

Table 2 Total fertility rates (TFR) and age-specific fertility rates among women aged 15-49, various surveys in Bangladesh

\begin{tabular}{|c|c|c|c|c|c|c|c|c|c|}
\hline $\begin{array}{c}\text { Age } \\
\text { group }\end{array}$ & $\begin{array}{l}1975 \\
\text { BFS }\end{array}$ & $\begin{array}{l}1989 \\
\text { BFS }\end{array}$ & $\begin{array}{c}\text { 1993-1994 } \\
\text { BDHS }\end{array}$ & $\begin{array}{c}\text { 1996-1997 } \\
\text { BDHS }\end{array}$ & $\begin{array}{l}\text { 1999-2000 } \\
\text { BDHS }\end{array}$ & $\begin{array}{c}2004 \\
\text { BDHS }\end{array}$ & $\begin{array}{c}2007 \\
\text { BDHS }\end{array}$ & $\begin{array}{c}2011 \\
\text { BDHS }\end{array}$ & $\begin{array}{c}2014 \\
\text { BDHS }\end{array}$ \\
\hline $15-19$ & 109 & 182 & 140 & 147 & 144 & 135 & 126 & 118 & 113 \\
\hline $20-24$ & 289 & 260 & 196 & 192 & 188 & 192 & 173 & 153 & 143 \\
\hline 25-29 & 291 & 225 & 158 & 150 & 165 & 135 & 127 & 107 & 110 \\
\hline $30-34$ & 250 & 169 & 105 & 96 & 99 & 83 & 70 & 56 & 57 \\
\hline 35-39 & 185 & 114 & 56 & 44 & 44 & 41 & 34 & 21 & 25 \\
\hline $40-44$ & 107 & 56 & 19 & 18 & 18 & 16 & 10 & 6 & 4 \\
\hline 45-49 & 35 & 18 & 14 & 6 & 3 & 3 & 1 & 3 & 4 \\
\hline TFR & 6.3 & 5.1 & 3.4 & 3.3 & 3.3 & 3.0 & 2.7 & 2.3 & 2.3 \\
\hline
\end{tabular}

From Table 2, it may be observed that the total fertility rate was 6.3 births per thousand women in 1975, and that for 2014 it was 2.3 births per thousand women, which is a decrease of approximately two-thirds over the last three decades. An inspection of the adjustments in the age-specific fertility rates demonstrates that the pinnacle of childbearing age occurred in the age group 
20-24, while the most significant total change in fertility likewise happened in this age group, declining from 192 births for every thousand women in the 2004 BDHS to 143 births for each thousand women in the 2014 BDHS.

\section{MEAN NUMBER OF LIVING CHILDREN ACCORDING TO BACKGROUND CHARACTERISTICS}

One simple measure of fertility is the average number of children ever born per woman, and in this study the number of living children is used as a measure of fertility. Since the explanatory variables (such as education, religion, and occupation) may be interlinked, it may be difficult to determine their relative impact on fertility. The socioeconomic differential in fertility occupies an essential position in demographic research (Kabir et al. 1994). Fertility levels are likely to change for different socioeconomic subgroups, while a higher level of fertility is typically observed for those with a lower educational level. On the contrary, lower fertility is observed in the group of those with a higher education. The fertility differential is presented in this analysis to see how it differs according to its various socioeconomic determinants. The study here includes only women married at the time of the survey whose complete demographic and socioeconomic characteristics were identifiable. Table 3 shows that the highest mean number of living children was found among illiterate respondents (3.18) followed by primary educated (2.43) respondents. This study confirms the inverse relationship between female educational attainment and fertility. The husband's educational attainments are also inversely related to the number of children, as with the educational status of the primary respondent.

Table 3 Mean number of living children per respondent according to socio-demographic characteristics

\begin{tabular}{|c|c|c|}
\hline Background Characteristics & No. of Respondents & $\begin{array}{c}\text { Mean number of living } \\
\text { children }\end{array}$ \\
\hline Respondent's education & \multicolumn{2}{|c|}{} \\
\hline $\begin{array}{c}\text { Illiterate } \\
\text { Primary } \\
\text { Secondary } \\
\text { Higher }\end{array}$ & 3949 & 3.18 \\
\cline { 2 - 3 } & 4916 & 2.43 \\
\cline { 2 - 3 } & 6503 & 1.73 \\
\hline Respondent Currently Working & 1490 & 1.24 \\
\hline No & 11486 & 2.14 \\
\cline { 2 - 3 } Yes & 5371 & 2.42 \\
\hline
\end{tabular}




\begin{tabular}{|c|c|c|}
\hline Background Characteristics & No. of Respondents & $\begin{array}{c}\text { Mean number of living } \\
\text { children }\end{array}$ \\
\hline \multicolumn{3}{|l|}{ Husband's Education } \\
\hline \multirow{4}{*}{$\begin{array}{c}\text { Illiterate } \\
\text { Primary } \\
\text { Secondary } \\
\text { Higher }\end{array}$} & 4715 & 2.83 \\
\hline & 4680 & 2.30 \\
\hline & 5085 & 1.86 \\
\hline & 2379 & 1.70 \\
\hline \multicolumn{3}{|l|}{ Husband's Occupation } \\
\hline \multirow{4}{*}{$\begin{array}{c}\text { Agriculture } \\
\text { Service } \\
\text { Business } \\
\text { Others }\end{array}$} & 4264 & 2.62 \\
\hline & 4094 & 2.28 \\
\hline & 7854 & 1.97 \\
\hline & 645 & 2.49 \\
\hline \multicolumn{3}{|l|}{ Type of Place of Residence } \\
\hline \multirow{2}{*}{$\begin{array}{c}\text { Urban } \\
\text { Rural } \\
\end{array}$} & 4709 & 1.97 \\
\hline & 12149 & 2.33 \\
\hline \multicolumn{3}{|l|}{ Religion } \\
\hline \multirow{2}{*}{$\begin{array}{c}\text { Muslim } \\
\text { Non-Muslim }\end{array}$} & 15187 & 2.26 \\
\hline & 1670 & 2.00 \\
\hline \multicolumn{3}{|l|}{ Age at First Marriage } \\
\hline \multirow{2}{*}{$\begin{array}{l}>15 \text { years } \\
\leq 15 \text { years }\end{array}$} & 8614 & 2.55 \\
\hline & 8244 & 1.90 \\
\hline \multicolumn{3}{|l|}{ Access to Mass Media } \\
\hline \multirow{2}{*}{$\begin{array}{l}\text { No access } \\
\text { Access }\end{array}$} & 6235 & 2.66 \\
\hline & 10622 & 1.98 \\
\hline \multicolumn{3}{|l|}{ Socioeconomic Status } \\
\hline \multirow{3}{*}{$\begin{array}{c}\text { Poor } \\
\text { Middle } \\
\text { Rich }\end{array}$} & 6320 & 2.50 \\
\hline & 3394 & 2.26 \\
\hline & 7143 & 1.98 \\
\hline \multicolumn{3}{|l|}{ Marital Duration } \\
\hline \multirow{4}{*}{$\begin{array}{c}\text { 0-8 years } \\
\text { 9-16 years } \\
\text { 17-24 years } \\
\text { Over } 24 \text { years }\end{array}$} & 6264 & 1.06 \\
\hline & 5500 & 2.48 \\
\hline & 3725 & 3.26 \\
\hline & 1368 & 3.77 \\
\hline Overall & 16858 & 2.23 \\
\hline
\end{tabular}

Source: Author's elaboration using BDHS 2014 survey dataset

The occupation of respondents' husband is considered an index of socioeconomic status in the study of fertility differentials. The study identified that among the four occupational groups the average number of children was highest among women whose husbands were engaged in agriculture and lowest for those whose husbands were engaged in providing services. The reason for the former finding is that such parents desire sons to support them in old age (Sekher - Hatti 2010; Larsen 2011). 
Progress with decreasing fertility is much of the time viewed as a phenomenon that begins in urban areas and spreads to the countryside. Surely, urban fertility has more dependably been resolved (i.e. decreased) than rural fertility (United Nations 1987). Table 3 confirms the lower levels of fertility in urban areas than rural ones. Fertility is also affected and influenced by the preaching of the religious. Muslim respondents had more offspring (2.26) on average than NonMuslim(2.00) respondents in Bangladesh. Table 3 also illustrates that respondents who had access to mass media and belong to the highest socioeconomic stratum had on average fewer children than those had no access to media and belong to the lowest socioeconomic stratum. Thus, such socioeconomic variability should be minimized to reduce the growth of the population. Moreover, duration of marriage may be considered a determinant of parity-dependent fertility (Bavel 2003). Table 3 confirms that the longer the duration of marital life, the higher the average number of living children.

\section{PARITY PROGRESSION OF RESPONDENTS BY DIFFERENT GENDER COMPOSITION}

For this study the sample is divided by parity and sex composition; namely: parity 1 ( 0 or 1 son), parity 2 ( 0,1 or 2 sons), parity 3 ( $0,1,2$ or 3 sons), and parity 4 $(0,1,2,3$ or 4 sons). In this study "sex composition" indicates different possible combinations of all sons and daughters at a given parity, without considering birth order at different parities. The current analysis considers those women who have at least one child.

In this study, a total of 15,241 respondents satisfied the fertility conditions. Among them, 227 respondents were eliminated because they had one or more multiple births (twins, triplets, etc.) at any parity. After the exclusion of these respondents, the final sample consisted of 15,014 women who had 38,526 living children up to parity 5 . Table 4 shows that out of the 15,014 women who had a son at first birth, 75.16 percent had at least one subsequent delivery (76.15 percent of those who had a daughter). At parity 2, 64.32 percent of women who had no sons moved to parity 3 ; the proportion dropped to 60.37 percent for women with one son and 57.49 percent for women with two sons. At parity 3, 59.56 percent of women with no sons progressed to the next parity, compared with 54.72 percent with one son, 50.45 percent with two sons, and 53.61 percent with three sons. At parity 4, women with no sons had a 51.30 percent chance of moving to parity 5 ; the proportion was 53.99 percent for women with one son, 50.37 percent for women with two sons, 51.67 percent for women with three sons and 57.87 percent for women with four sons. 
Table 4 Percentage distribution of respondents who continued childbearing according to different parity

\begin{tabular}{|c|c|c|}
\hline Parities & No. of Women & Parity Progression \\
\hline \multirow{3}{*}{$\begin{array}{c}\text { Parity } 1 \\
0 \text { son } \\
1 \text { son }\end{array}$} & \multirow{3}{*}{15,014} & \\
\hline & & 76.15 \\
\hline & & 75.16 \\
\hline \multirow{4}{*}{$\begin{array}{c}\text { Parity } 2 \\
0 \text { son } \\
1 \text { son } \\
2 \text { sons }\end{array}$} & \multirow{4}{*}{11,279} & \\
\hline & & 64.32 \\
\hline & & 60.37 \\
\hline & & 57.49 \\
\hline \multirow{5}{*}{$\begin{array}{c}\text { Parity } 3 \\
0 \text { son } \\
1 \text { son } \\
2 \text { sons } \\
3 \text { sons }\end{array}$} & \multirow{5}{*}{6,765} & \\
\hline & & 59.56 \\
\hline & & 54.72 \\
\hline & & 50.45 \\
\hline & & 53.61 \\
\hline \multirow{6}{*}{$\begin{array}{c}\text { Parity } 4 \\
0 \text { son } \\
1 \text { son } \\
2 \text { sons } \\
3 \text { sons } \\
4 \text { sons }\end{array}$} & \multirow{6}{*}{3,594} & \\
\hline & & 51.30 \\
\hline & & 53.99 \\
\hline & & 50.37 \\
\hline & & 51.67 \\
\hline & & 57.87 \\
\hline Parity 5 & 1,874 & \\
\hline
\end{tabular}

Source: Author's elaboration using BDHS 2014 survey dataset

At parity 2 and above, respondents with no sons were more liable to continue childbearing than those that have son(s). These results show the effect of son preference on continued childbearing. Therefore, an effective program launched by the government and/or private organizations to discourage son preference might help to reduce the fertility rate. In the next section, we show how at different parities background characteristics were tested to identify the relative importance of different variables on fertility in Bangladesh.

\section{TEST OF ASSOCIATION AND LOGISTIC REGRESSION ANALYSIS}

The measures of association refer to a wide variety of coefficients that measure the statistical strength of the relationship between variables of interest; these measures of strength or association can be described in several ways, depending on the analysis. All the independent variables except for religion selected for this study were highly significantly associated with parity 1 (Table 5). 
Table 5 Test of association between different parities and individual characteristics of respondents

\begin{tabular}{|c|c|c|c|c|}
\hline Background Characteristics & \multicolumn{4}{|c|}{ Parities } \\
\hline & Parity 1 & Parity 2 & Parity 3 & Parity 4 \\
\hline Respondent's education & $1338.5^{* * *}$ & $1293.04^{* * *}$ & $414.1^{* * *}$ & $63.29^{* * *}$ \\
\hline Respondent Currently Working & $126.9^{* * *}$ & 2.3 & 0.07 & $5.84^{* *}$ \\
\hline Husband's Education & $558.6^{* * *}$ & $637.9^{* * *}$ & $146.3^{* * *}$ & $17.68^{* * *}$ \\
\hline Husband's Occupation & $187.5^{* * *}$ & $189.9^{* * *}$ & $141.6^{* * *}$ & $7.30^{*}$ \\
\hline Type of Place of Residence & $74.1^{* * *}$ & $98.06^{* * *}$ & $42.8^{* * *}$ & $6.21^{* *}$ \\
\hline Religion & 0.5 & $32.6^{* * *}$ & $25.1^{* * *}$ & $3.83^{*}$ \\
\hline Age at First Marriage & $345.12^{* * *}$ & $213.4^{* * *}$ & $76.7^{* * *}$ & 2.54 \\
\hline Access to Mass Media & $264.9^{* * *}$ & $286.7^{* * *}$ & $246.1^{* * *}$ & $25.83^{* * *}$ \\
\hline Socioeconomic Status & $159.6^{* * *}$ & $192.5^{* * * *}$ & $100.8^{* * *}$ & $9.7^{* *}$ \\
\hline Marital Duration & $5410.8^{* * *}$ & $2339.6^{* * *}$ & $697.3^{* * *}$ & $212.9^{* * *}$ \\
\hline
\end{tabular}

Source: Author's elaboration using BDHS 2014 survey dataset. Note: $* p<0.10, * * p<0.05$; ***p<0.01

At parity 2 and parity 3, only the working status of the respondents was not found to be significantly associated with parity movement, whereas at parity 4 age at first marriage was not significantly associated with parity movement.

To identify the relative contribution of the category of different variables, multivariate regression was employed (Table 6) concerning the variables found to be significant in the bivariate analysis.

At parity 2, the odds ratio of respondents with a son in Bangladesh is 0.741, indicating that respondents those who had one son were 25.9 percent less likely to have another child (move to parity 3 ) than those had no sons, whereas respondents at parity 3 who had one son were 23.4 percent less likely to move to parity 4 than those had no sons (all have daughters). This result is a clear indication of son preference in Bangladesh. At parity 2, the odds of having another child were lower among women with two sons (odds ratio 0.676) than among women with no sons (two daughters). At parity 3, the odds of parity progression were lower among women with three sons (0.646) or two sons (0.599) than among women with no sons (only daughters). The results indicate that women with at least one son are less likely to continue childbearing than women with all daughters. The above findings are supported by Chaudhuri (2012) through multivariate analyses: the author also finds that women with no sons are more likely than women with no daughters to keep childbearing at parities 1-4. Another unique component of the research described in this article is that it inspected parity movement driven by parity progression for sons through formal, parity-specific multivariate regression. The analysis also shows that even after adjustment for socioeconomic and demographic factors, having 
a higher proportion of daughters is associated with different demographic and socioeconomic variables. Women with a higher education were less likely to move next parity than those have no formal education. A similar result was found for partners' education. From the analysis it was found that rural respondents are more likely to have subsequent births than their urban counterparts. Clark (2000) identified the fact that less educated, rural, and Muslim couples in India have the highest proportion of sons. The study also reveals the same result in Bangladesh. Furthermore, the study identified that there is a vast difference in fertility behavior between respondents who had access to mass media and those had no access. At parity 2 and parity 3, respondents who had access to any media in Bangladesh were 25.2 percent and 46.5 percent (respectively) less likely to have a subsequent birth than those had no access to mass media.

Table 6 Estimated odds ratio from binary logistic regression models between selected measures and progression to next parity

\begin{tabular}{|c|c|c|c|c|}
\hline & \multicolumn{4}{|c|}{ Odds Ratio } \\
\hline Background Characteristics & Parity 1 & Parity 2 & Parity 3 & Parity 4 \\
\hline \multicolumn{5}{|l|}{ No. of Sons } \\
\hline \multirow{5}{*}{$\begin{array}{c}0 \text { (RC) } \\
1 \\
2 \\
3 \\
4\end{array}$} & 1.00 & 1.00 & 1.00 & 1.00 \\
\hline & 0.941 & $0.741 * * *$ & $0.766^{* * *}$ & 1.082 \\
\hline & n.a. & $0.676 * * *$ & $0.599 * * *$ & 0.891 \\
\hline & n.a. & n.a. & $0.646^{* * *}$ & 0.925 \\
\hline & n.a. & n.a. & na & 1.162 \\
\hline \multicolumn{5}{|l|}{ Respondent's Education } \\
\hline \multirow{4}{*}{$\begin{array}{c}\text { Illiterate (RC) } \\
\text { Primary } \\
\text { Secondary } \\
\text { Higher }\end{array}$} & 1.00 & 1.00 & 1.00 & 1.00 \\
\hline & $0.821 * *$ & $0.680 * * *$ & $0.742 * * *$ & $0.802 * * *$ \\
\hline & $0.611 * * *$ & $0.486 * * *$ & $0.546^{* * *}$ & $0.693 * * *$ \\
\hline & $0.360 * * *$ & $0.238 * * *$ & $0.225^{* * *}$ & 0.719 \\
\hline \multicolumn{5}{|l|}{ Respondent Currently Working } \\
\hline \multirow{2}{*}{$\begin{array}{c}\text { No }(\mathrm{RC}) \\
\text { Yes }\end{array}$} & 1.00 & --- & --- & 1.00 \\
\hline & 1.035 & --- & --- & $1.174 * *$ \\
\hline \multicolumn{5}{|l|}{ Husband's Education } \\
\hline \multirow{4}{*}{$\begin{array}{l}\text { Illiterate (RC) } \\
\text { Primary } \\
\text { Secondary } \\
\text { Higher }\end{array}$} & 1.00 & 1.00 & 1.00 & 1.00 \\
\hline & 0.889 & 0.910 & 1.024 & $1.276^{* * *}$ \\
\hline & $0.725 * * *$ & $0.678 * * *$ & 0.888 & 0.977 \\
\hline & $0.819^{*}$ & $0.573 * * *$ & 0.989 & 0.873 \\
\hline \multicolumn{5}{|l|}{ Husband's Occupation } \\
\hline \multirow{4}{*}{$\begin{array}{c}\text { Agriculture (RC) } \\
\text { Service } \\
\text { Business } \\
\text { Others }\end{array}$} & 1.00 & 1.00 & 1.00 & 1.00 \\
\hline & 1.067 & $1.297 * * *$ & $0.844 * *$ & $1.176^{*}$ \\
\hline & 0.949 & 0.947 & $0.775 * * *$ & 1.103 \\
\hline & 0.877 & $1.276^{*}$ & $1.282^{*}$ & 1.207 \\
\hline
\end{tabular}




\begin{tabular}{|c|c|c|c|c|}
\hline & \multicolumn{4}{|c|}{ Odds Ratio } \\
\hline Background Characteristics & Parity 1 & Parity 2 & Parity 3 & Parity 4 \\
\hline \multirow{2}{*}{$\begin{array}{c}\text { Urban (RC) } \\
\text { Rural }\end{array}$} & 1.00 & 1.00 & 1.00 & 1.00 \\
\hline & $1.240 * * *$ & $1.19 * * *$ & 1.087 & 1.15 \\
\hline \multicolumn{5}{|l|}{ Religion } \\
\hline \multirow{2}{*}{$\begin{array}{l}\text { Muslim (RC) } \\
\text { Non-Muslim }\end{array}$} & --- & 1.00 & 1.00 & 1.00 \\
\hline & --- & $0.637 * * *$ & $0.571^{* * *}$ & $0.655^{* * *}$ \\
\hline \multicolumn{5}{|l|}{ Age at First Marriage } \\
\hline \multirow{2}{*}{$\begin{array}{c}>15 \text { years }(\mathrm{RC}) \\
\leq 15 \text { years }\end{array}$} & 1.00 & 1.00 & 1.00 & --- \\
\hline & $1.128^{* *}$ & $1.138 * * *$ & 0.961 & --- \\
\hline \multicolumn{5}{|l|}{ Access to Mass Media } \\
\hline \multirow{2}{*}{$\begin{array}{c}\text { No access }(\mathrm{RC}) \\
\text { Access }\end{array}$} & 1.00 & 1.00 & 1.00 & 1.00 \\
\hline & $0.817 * * *$ & $0.748 * * *$ & $0.535 * * *$ & $0.722 * * *$ \\
\hline \multicolumn{5}{|l|}{ Socioeconomic Status } \\
\hline \multirow{3}{*}{$\begin{array}{c}\text { Poor }(\mathrm{RC}) \\
\text { Middle } \\
\text { Rich }\end{array}$} & 1.00 & 1.00 & 1.00 & 1.00 \\
\hline & $0.853 * *$ & 1.1004 & 0.986 & 1.04 \\
\hline & 0.901 & $0.889^{*}$ & 0.927 & 0.953 \\
\hline \multicolumn{5}{|l|}{ Marital Duration } \\
\hline \multirow{4}{*}{$\begin{array}{l}\text { 0-8 years }(\mathrm{RC}) \\
\text { 9-16 years } \\
17-24 \text { years } \\
\text { Over } 24 \text { years }\end{array}$} & 1.00 & 1.00 & 1.00 & 1.00 \\
\hline & $13.62 * * *$ & $5.99 * * *$ & $6.92 * * *$ & 1.93 \\
\hline & $31.34 * * *$ & $16.34 * * *$ & $16.01 * * *$ & $4.74 * * *$ \\
\hline & $61.66^{* * *}$ & $33.48 * * *$ & $28.05 * * *$ & $7.30 * * *$ \\
\hline Constant & 1.150 & $0.556^{* * *}$ & $0.314 * * *$ & $0.282 * * *$ \\
\hline
\end{tabular}

Source: Author's elaboration using BDHS 2014 survey dataset. Note: $R C(1.00)=$ Reference Category, ${ }^{*} p<0.10$, ${ }^{* *} p<0.05, *^{* *} p<0.01$ and (---) indicates insignificant in bivariate analysis. 'n.a.' indicates not applicable.

Wealth index, an indicator of economic development, is significantly correlated to fertility (in a negative direction). This result also indicates the same: the more wealth respondents have, the less likely they are to have a subsequent birth. Moreover, the analysis reveals that the duration of marriage has a positive impact on fertility.

\section{CONCLUSION AND POLICY IMPLICATIONS}

A preference for sons is both a consequence and a cause of the low status of women. It is a consequence because it arises as a result of women being considered as playing only unimportant roles, and thus of less value. This undervaluation, in turn, leads to lower investment in females as a result of which they are only able to play an unimportant role in society, causing further lowering of their status. In all cases, this fosters a preference for sons, whereby the allocation of prestige, power, and resources depend on the physical characteristics of sex. In 
addition, findings from the parity progression analysis show that women with only son(s) are less likely to move to the next parity than women with only daughter(s). The result further confirms the son preference among couples in Bangladesh. Thus, similar findings of parity progression confirm that a desire for sons is relatively high among couples, which is one of the prime constraints on the reduction of fertility in Bangladesh.

From the analysis of fertility behavior, it may be mentioned here that there are many different motivations for having sons and therefore changes in a single factor may not be sufficient to spur a fertility decline. The desire to have sons can affect fertility decisions and thus can alter the size and sex composition of children within a given family. However, the findings of this study suggest that the emphasis should be on factors such as education, strictly adhering to the legal age for marriage of females, creating job opportunities, improving the socioeconomic conditions and the status of women, and also reducing parental dependence on living children. These are well-known and oft-repeated recommendations supported by most studies on the determinants of fertility. Therefore, this study confirms the relevance of these factors for fruitful population policy in Bangladesh.

Policymakers have suggested promoting the highest educational attainments to reduce son preference which drives parity progression. Although female education is strongly encouraged in Bangladesh and the government provides a stipend to women to continue until higher secondary education, such efforts are likely to have weak effects in dominantly patriarchal Bangladesh. Therefore, there is an urgent need to deal with patriarchal values which infer that sons are more valuable than daughters. Moreover, if the high fertility in Bangladesh is strictly a consequence of a preference for male children, then a decline in ideal family formation and a weakening of son preference would reduce fertility by bringing it close to the replacement level. This level may be reached by strengthening public programs that promote a better standard of life and equal rights for women and men, thereby helping ensure that a sufficient number of surviving children, irrespective of son preference, can provide their parents with the expected help and security in old age.

\section{REFERENCES}

Adebowale, Stephen Ayo - Martin Enoch Palamuleni (2015), "Influence of gender preference and sex composition of surviving children on childbearing intention among high fertility married women in stable union in Malawi", Africa Health Science Vol. 15, No 1, pp. 150-160. http://dx.doi.org/10.4314/ ahs.v15i1.21 
Alamgir, Dewan A. H. (2009), "State of Microfinance in Bangladesh", Institute of Microfinance, State of Microfinance in SAARC Countries. Available at inm.org.bd/wp-content/themes/inm/pdf/Bangladesh.pdf

Bangladesh Bureau of Statistics (2017), "Quarterly Labor Force Survey 20152016", Statistics and Information Division, Ministry of Planning, Dhaka.

Bangladesh Bureau of Statistics (2015), "Population and Housing Census 2011", Statistics and Information Division, Ministry of Planning, Dhaka.

Basu, Alaka Malwade - Sajeda Amin (2000), "Conditioning factors for fertility decline in Bengal: History, language identity, and openness to innovations", Population and Development Review Vol. 26, No 4, pp. 761-794. https://doi. org/10.1111/j.1728-4457.2000.00761.x

Basu, Deepankar - Robert De Jong (2010), "Son targeting fertility behavior: some consequences and determinants". Demography Vol. 47, No 2, pp. 521536. https://doi.org/10.1353/dem.0.0110

Bavel, Jan Van (2003), "Does an effect of marriage duration on pre-transition fertility signal parity-dependent control? An empirical test in nineteenthcentury Leuven, Belgium", Population Studies Vol. 57, No 1, pp. 55-62. http://www.jstor.org/stable/3092903.

Boer, Andrea den - Valerie Hudson (2017), "Patrilineality, Son Preference, and Sex Selection in South Korea and Vietnam", Population and Development Review Vol. 43, No 1, pp. 119-147. https://doi.org/10.1111/padr.12041

Calhoun, Lisa M. - Priya Nanda - Ilene S. Speizer - Meenakshi Jain (2013), "The effect of family sex composition on fertility desires and family planning behaviors in urban Uttar Pradesh, India", Reproductive health Vol. 10, No 1, pp. 48. https://doi.org/10.1186/1742-4755-10-48

Chaudhuri, Sanjukta (2012), "The Desire for Sons and Excess Fertility: A HouseholdLevel Analysis of Parity Progression in India", International Perspectives on Sexual and Reproductive Health Vol. 38, No 4, pp. 178-186. doi: 10.1363/3817812 Chattopadhyay, Aparajita - Baishali Goswami (2007), "Status of women in two Bengals: Evidence from large scale surveys", Journal of Biosocial Science Vol. 39, No 2, pp. 276-286. https://doi.org/10.1017/S002193200600126x

Clark, Shelley (2000), "Son Preference and Sex Composition of Children: Evidence from India", Demography Vol. 37, No 1, pp.95-108. https://doi. org/10.2307/2648099

Hank, Karsten - Hans-Peter Kohler (2000), "Gender preferences for children in Europe: empirical results from 17 FFS countries". Demographic Research Vol. 2, No 1, pp.133-144. doi: 10.4054/DemRes.2000.2.1

Huiying, Li (2016), "Son Preference and the Tradition of Patriarchy in Rural China", Comparative Feminist Studies Series, Palgrave Macmillan, New York. https://doi.org/10.1057/9781137550804_7 
Kabeer, Naila - Lopita Huq - Simeen Mahmud (2014), "Diverging Stories of "Missing Women" in South Asia: Is Son Preference Weakening in Bangladesh?", Feminist Economics Vol. 20, No 4, pp. 138-163. http://dx.doi.or $\mathrm{g} / 10.1080 / 13545701.2013 .857423$

Kabir, M. - Ruhul Amin - Ashraf Uddin Ahmed - Jamir Chowdhury (1994), "Factors affecting desired family size in Bangladesh", Journal of Biosocial Science Vol. 26, No 3, pp. 369-375.

Kamal, Nashid - Rafiqul Huda Chaudhury (2003), "Plateauing TFR Bangladesh: An exploratory analysis", Asian Profile Vol. 31, No 2, pp. 157-166.

Khan, M. Asaduzzaman -P. A. Khanum (2000), "Influence of son preference on contraceptive use in Bangladesh", Asia-Pacific population journal Vol. 15, No 3, pp. 43-56. https://www.popline.org/node/171510.

Larsen, Mattias (2011), "Vulnerable Daughters in India: Culture, Development and Changing Contexts", New Delhi, India: Routledge. https://trove.nla.gov. $\mathrm{au} / \mathrm{version} / 165474548$

Leone, Tiziana - Zoë Matthews - Gianpiero Dalla Zuanna (2003), "Impact and determinants of Son preference in Nepal", International family planning perspectives Vol. 29, No 2, pp. 69-75. doi: 10.1363/ifpp.29.069.03

Mace, Ruth - Rebecca Sear (1997), "Birth interval and the sex of children in a traditional African population: an evolutionary analysis", Journal of Biosocial Science Vol. 29, No 4, pp. 499-507.

Ministry of Environment and Forests (2012), "Rio + 20: National Report on Sustainable Development", Peoples' Republic of Bangladesh, Bangladesh Secretariat, Dhaka. Available at https://sustainabledevelopment.un.org/ content/documents/981bangladesh.pdf

National Institute of Population Research and Training (2001), "Bangladesh Demographic and Health Survey 1999-2000", .Dhaka, Bangladesh and Calverton, Maryland [USA]: National Institute of Population Research and Training (NIPORT), Mitra and Associates, and ORC Macro. Available at http://dhsprogram.com/pubs/pdf/FR119/FR119.pdf.

National Institute of Population Research and Training (2005), "Bangladesh Demographic and Health Survey 2004", Dhaka, Bangladesh and Calverton, Maryland [USA]: National Institute of Population Research and Training (NIPORT), Mitra and Associates, and ORC Macro. Available at https:// dhsprogram.com/pubs/pdf/fr165/fr-bd04[fr165].pdf

National Institute of Population Research and Training (2009), "Bangladesh Demographic and Health Survey 2007", Dhaka, Bangladesh and Calverton, Maryland [USA]: National Institute of Population Research and Training (NIPORT), Mitra and Associates, and ORC Macro. Available at https:// dhsprogram.com/pubs/pdf/FR207/FR207[April-10-2009].pdf 
National Institute of Population Research and Training (2012), "Bangladesh Demographic and Health Survey 2011", Dhaka, Bangladesh and Calverton, Maryland [USA]: National Institute of Population Research and Training (NIPORT), Mitra and Associates, and ORC Macro. Available at https://dhsprogram.com/pubs/pdf/fr265/fr265.pdf

National Institute of Population Research and Training (2016), "Bangladesh Demographic and Health Survey 2014", Dhaka, Bangladesh and Calverton, Maryland [USA]: National Institute of Population Research and Training (NIPORT), Mitra and Associates, and ORC Macro. Available at https:// dhsprogram.com/pubs/pdf/FR311/FR311.pdf

Rahman, Mizanur - Julie Da Vanzo (1993), "Gender Preference and birth spacing in Matlab, Bangladesh", Demography Vol. 30, No 3, pp. 315-332.

Schurmann, Anna T. (2009), "Review of the Bangladesh female secondary school stipend project using a social exclusion framework", Journal of health, population, and nutrition Vol. 27, No 4, pp. 505-517. https://doi.org/10.3329/ jhpn.v27i4.3393.

Seidl, Christian (1995), "The desire for a son is the father of many daughters. A sex ratio paradox", Journal of Population Economics Vol. 8, No 2, pp.185-203. https://doi.org/10.1007/BF00166651

Sekher, T. V. - Neelambar Hatti (2010), "Disappearing Daughters and Intensification of Gender Bias: Evidence from Two Village Studies in South India", Sociological Bulletin Vol. 59, No 1, pp. 111-133. Retrieved from http:// www.jstor.org/stable/23620848.

Sloane, Douglas M. - Che-Fu Lee (1983), "Sex of previous children and intentions for further births in the United States, 1965-1976", Demography Vol. 20, No 3, pp. 353-367. https://doi.org/10.2307/2061247

Thompson, Thomas P. - Joaquin Sanabria (2010), "The division of labour and agricultural innovation in Bangladesh: dimensions of gender", International Center for Soil Fertility and Agricultural Development (IFDC), Alabama, USA.

United Nations (1987), "Fertility Behaviour in the Context of Development: Evidence from the World Fertility Survey", Population Studies, No. 100, New York. ST/ESA/SER.A/100.

Visaria, Abhijit (2015), "Religion and son preference in India and Bangladesh: Three essays on comparing Hindus and Muslims on son preference and sex differentials in child health", Available from ProQuest.AAI3721679. https:// repository.upenn.edu/dissertations/AAI3721679

Wood, Charles H. - Frank D. Bean (1977), "Offspring gender and family size: implications from a comparison of Mexican Americans and Anglo Americans", Journal of Marriage and the Family Vol. 39, No 1, pp. 129-139. 
World Bank. (2017). Available at https://data.worldbank.org/indicator/SP.POP. GROW

Zaman, Hassan (2004), "The Scaling-Up of Microfinance in Bangladesh: Determinants, Impact, and Lessons," World Bank Policy Research Working Paper no. 3398. 
